\title{
ANALISIS PRODUKTIVITAS WAKTU BONGKAR STEEL PRODUCT ANTARA SHIP CRANE DAN GANTRY LIFTING CRANE (GLC) PADA MV. VTC PHOENIX (PT. DAISY MUTIARA SAMUDRA)
}

\section{PRODUCTIVITY ANALYSIS OF STEEL PRODUCT BETWEEN SHIP CRANE AND GANTRY LIFTING CRANE (GLC) IN MV. VTC PHOENIX (PT. DAISY MUTIARA SAMUDRA)}

\author{
${ }^{a, 1^{*}}$ Vivian Karim Ladesi, Ali Afriyanto ${ }^{\text {b,2 }}$ \\ ${ }^{a}$ Dosen Pembimbing Prodi D III Transportasi, Jl. Rawamangun Muka, Jakarta Timur, Indonesia \\ ${ }^{\mathrm{b}}$ Mahasiswa Prodi D III Transportasi, Jl. Rawamangun Muka, Jakarta Timur, Indonesia \\ 1*Vivian Ladesi@unj.ac.id, ${ }^{2}$ alynt99@gmail.com \\ *corresponding e-mail: transportasiunj@yahoo.co.id
}

\begin{abstract}
This final project report aims to analyze the productivity of the time of loading steel products between ship cranes and gantry lifting cranes (GLC) at mv. vtc phoenix (PT. Daisy Mutiara Samudra) which is more effective between the two tools. As well as a graduation requirement from the Jakarta State University Diploma III Transportation study program. In preparing this final report task by collecting data in primary and secondary forms. Primary data is in the form of interviews and observations of ship crane and gantry lifting crane objects. Secondary data is in the form of manifest recap data and standard operating procedures. The time needed to unload the coils using the GLC is 8 hours 23 minutes and the time required to unload the coils using a ship crane is 10 hours. It can be concluded that the most effective tool in unloading coils is GLC, because it has a large carrying capacity.
\end{abstract}

Keywords : Productivity of loading time, effective, ship crane and gantry lifting crane $(G L C)$.

\begin{abstract}
ABSTRAK
Laporan tugas akhir tersebut bertujuan untuk menganalisis produktivitas waktu bongkar steel product antara ship crane dan gantry lifting crane (GLC) pada mv. vtc phoenix (PT. Daisy Mutiara Samudra) yang lebih efektif diantara kedua alat tersebut. Sekaligus sebagai persyaratan kelulusan dari program studi Diploma III Transportasi Universitas Negeri Jakarta.

Dalam penyusunan tugas laporan akhir ini dengan mengumpulkan data dalam bentuk primer dan sekunder. Data primer berupa wawancara serta observasi obyek ship crane dan gantry lifting crane. Data sekunder berupa data rekap manifest dan standar operasional prosedur.
\end{abstract}


Waktu yang dibutuhkan untuk membongkar coils menggunakan GLC yaitu 8 jam 23 menit dan waktu yang dibutuhkan untuk membongkar coils menggunakan ship crane yaitu 10 jam. Dapat disimpulakan bahwa alat yang paling efektif dalam bongkar coils ialah GLC, karena mempunyai kapasitas angkut yang besar.

Kata kunci : Produktifitas waktu bongkar, efektif, ship crane dan gantry lifting crane (GLC).

\section{A. Pendahuluan}

Pelabuhan merupakan simpul transportasi laut yang menjadi fasilitas penghubung dengan daerah lain untuk melakukan aktivitas perdagangan. Pelabuhan memiliki peranan penting dalam perekonomian negara untuk menciptakan pertumbuhan ekonominya. pelabuhan adalah tempat yang terdiri dari daratan dan perairan di sekitarnya dengan batas-batas tertentu sebagai tempat kegiatan pemerintah dan kegiatan ekonomi dipergunakan sebagai tempat kapal bersandar, berlabuh, naik turun penumpang dan/atau bongkar muatan barang yang dilengkapi dengan fasilitas keselamatan pelayaran dan kegiatan penunjang pelabuhan serta sebagai tempat perpindahan intra dan antar moda transportasi. Untuk memperlancar arus barang dan jasa guna menjungjung kegiatan perdagangan di pelabuhan, maka di perlukan adanya sarana pengangkut yang memadai, yaitu pengangkutan melalui laut.

PT. Daisy Mutiara Samudra merupakan perusahaan swasta yang menangani bongkar muat kapal general cargo di pelabuhan tanjung priok. Pada perusahaan bongkar muat salah satu yang paling penting dalam produktivitas bongkar muat agar berjalan lancar dan efesien dalam waktu juga meminimalisasi biaya.

Definisi dari proses "bongkar" yaitu proses menurunkan barang dari kapal ke darat, sedangkan "muat" yaitu proses menaikan barang dari darat ke kapal. Yang di maksud dengan produktivitas pada proses bongkar muat adalah kecepatan bongkar muat untuk membongkar dan memuat barang dari dan ke atas kapal. Waktu yang dihabiskan kapal selama berada di pelabuhan akan sangat berpengaruh dalam efisiensi pengoprasian kapal tersebut. Semakin lama waktu kapal berada di pelabuhan maka semakin tidak efisiensi, karena akan memakan waktu yang lama dan biaya yang sangat tinggi.

Adanya beberapa alat yang menyebabkan produktivitas bongkar steel product yaitu di antara nya seperti alat gantry lifting crane dan ship crane. Gantry lifting crane alat yang memiliki kapasitas daya angkat beban 40,7 ton sedangkan ship crane mempunyai kapasitas daya angkat 30,7 ton. Kemudian sumber daya manusia memiliki peran dalam kelancaran proses bongkar muat, Sumber daya manusia di perusahaan bongkar muat juga harus berkordinasi oleh semua operator ship crane dan gantry lifting crane mv. vtc phoenix.

\section{B. Metode Penelitian}

Metode penelitian yang digunakan pada penelitian ini adalah metode kuantitatif. Data yang disajikan dalam tugas akhir ini adalah untuk memberikan informasi mengenai analisis data terkait dengan produktivitas waktu liftting antara GLC dan Ship crane yang berhubungan dengan waktu yang dibutuhkan untuk menghitung waktu bongkar dengan menggunakan alat GLC dan Ship Crane. 


\section{Hasil dan Pembahasan}

Perhitungan waktu lifting pada alat Ship crane untuk bongkar steel product

a. Kapasitas Coils 2 ton, perlifting 5 coils

Jumlah : 944 coils

Jumlah barang $x$ waktu lifting $=$ Coils per lifting

$944 \times 3=566,4$ menit dibulatkan 566 menit 5

566 menit : 2 gang $=283$ menit

b. Kapasitas Coils 8 ton, perlifting 2 coils

Jumlah : 32 coils

Jumlah barang $\mathrm{x}$ waktu lifting $=$ Coils per lifting

$\frac{32 \times 3}{2}=48$ menit

48 menit $: 2$ gang $=24$ menit

c. Kapasitas Coils 18 ton, perlifting 1 coils

Jumlah : 105 coils

$\underline{\text { Jumlah barang } \mathrm{x} \text { waktu lifting }=}$ Coils per lifting

$105 \times 3=315$ menit 1

315 menit $: 2$ gang $=157,5$ menit dibulatkan 158 menit

d. Kapasitas Coils 19 ton, perlifting 1 coils

Jumlah 10 coils

Jumlah barang $\mathrm{x}$ waktu lifting $=$ Coils per lifting

$\underline{10 \times 3}=30$ menit 1

30 menit : 2 gang $=15$ menit 
Total keseluruhan waktu lifting Coils 2 ton +8 ton +18 ton +19 ton menggunakan Ship Crane

283 menit +24 menit +158 menit +15 menit $=480$ menit

480 menit : $60=8 \mathrm{jam}$

\section{Perhitungan waktu lifting pada gantry lifting crane untuk bongkar steel product}

a. Kapasitas Coils 2 ton, perlifting 10 coils

Jumlah : 944 coils

$\underline{\text { Jumlah barang } x \text { waktu lifting }=}$

Coils per lifting

$\underline{944 \times 5}=472$ menit

10

472 menit : 2 gang $=236$ menit

b. Kapasitas Coils 8 ton, perlifting 3 coils

Jumlah : 32 coils

Jumlah barang $\mathrm{x}$ waktu lifting $=$ Coils per lifting

$\underline{32 \times 4}=42,6$ menit dibulatkan 43 menit 3

43 menit : 2 gang $=21,5$ menit dibulatkan 22 menit

c. Kapasitas Coils 18 ton, perlifting 1 coil

Jumlah : 105 coils

Jumlah barang $\mathrm{x}$ waktu lifting $=$ Coils per lifting

$\underline{105 x} 4=210$ menit

2

210 menit $: 2$ gang $=105$ menit

d. Kapasitas Coils 19 ton, perlifting 1 coil

Jumlah 10 coils

Jumlah barang $\mathrm{x}$ waktu lifting $=$ Coils per lifting

$\underline{10 \mathrm{x} 4}=40$ menit

1

40 menit : 2 gang $=20$ menit 
Total keseluruhan waktu lifting coils $: 2$ ton +8 ton +18 ton +19 ton menggunakan Gantry Lifting Crane yaitu adalah :

236 menit +22 menit +105 menit +20 menit $=383$ menit

383 menit : $60=6$ jam 23 menit

Produktivitas waktu bongkar dan Jumlah Lifting Steel Product antara Gantry Lifting Crane dan Ship Crane

Jumlah Produktivitas Lifting Antara Ship Crane dan Glc

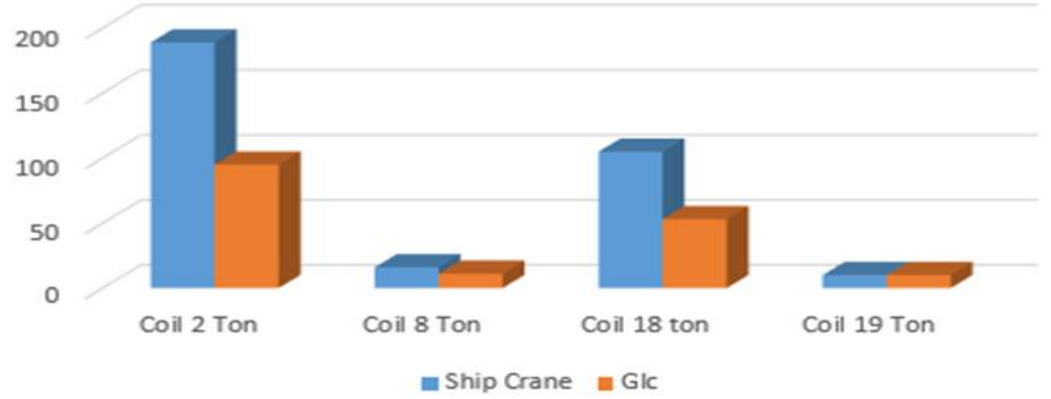

Gambar 1 Jumlah Produktivitas Lifting Antara GLC dan Ship Crane

Keterangan Gambar :

a. Jumlah Lifting Ship Crane

1. Coils 2 Ton $=189$ kali lifting

2. Coils 8 Ton $=16$ kali lifting

3. Coils 18 Ton $=105$ kali lifting

4. Coils 19 Ton $=10$ kali lifting

b. Jumlah Lifting Gantry Lifting Crane

1. Coils 2 Ton $=95$ kali lifting

2. Coils 8 Ton $=11$ kali lifting

3. Coils 18 Ton $=53$ kali lifting

4. Coils 19 Ton $=10$ kali lifting

\section{Jumlah Produktivitas Waktu Lifting Antara Ship Crane dan Glc}

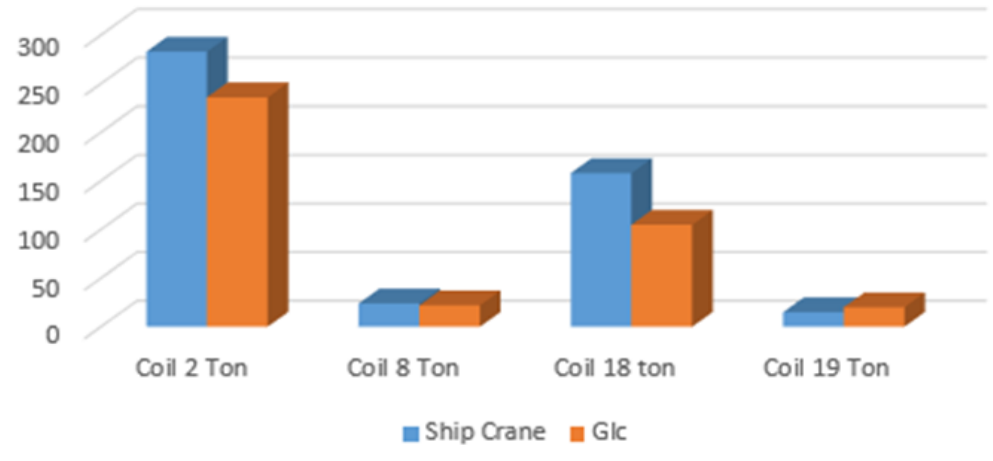

Gambar 2 Jumlah Produktivitas Waktu Lifting Antara GLC dan Ship Crane 
Keterangan Gambar :

a. Waktu Lifting Ship Crane

1. Coils 2 Ton $=283$ menit

2. Coils 8 Ton $=24$ menit

3. Coils 18 Ton $=158$ menit

4. Coils 19 Ton $=15$ menit

b. Waktu Lifting Gantry Lifting Crane

1. Coils 2 Ton $=236$ menit

2. Coils 8 Ton $=22$ menit

3. Coils 18 Ton $=105$ menit

4. Coils 19 Ton $=20$ menit

\section{Hasil produktivitas waktu bongkar steel product antara gantry lifting crane dan ship} crane

Berdasarkan dari pembahasan diatas yang dipaparkan, dapat dilihat bahwa Gantry lifting crane lebih cepat untuk proses bongkar dengan membutuhkan waktu hanya 8 jam 23 menit sedangkan menggunakan ship crane membutuhkan waktu 10 jam. Hal ini di katakan bahwa gantry lifting crane lebih efektif ketimbang ship crane dalam waktu.

Dalam jumlah lifiting gantry lifting crane juga unggul dengan mempunyai 169 lifting yang sedikit ketimbang dari ship crane yaitu 320 lifting yang lebih banyak.

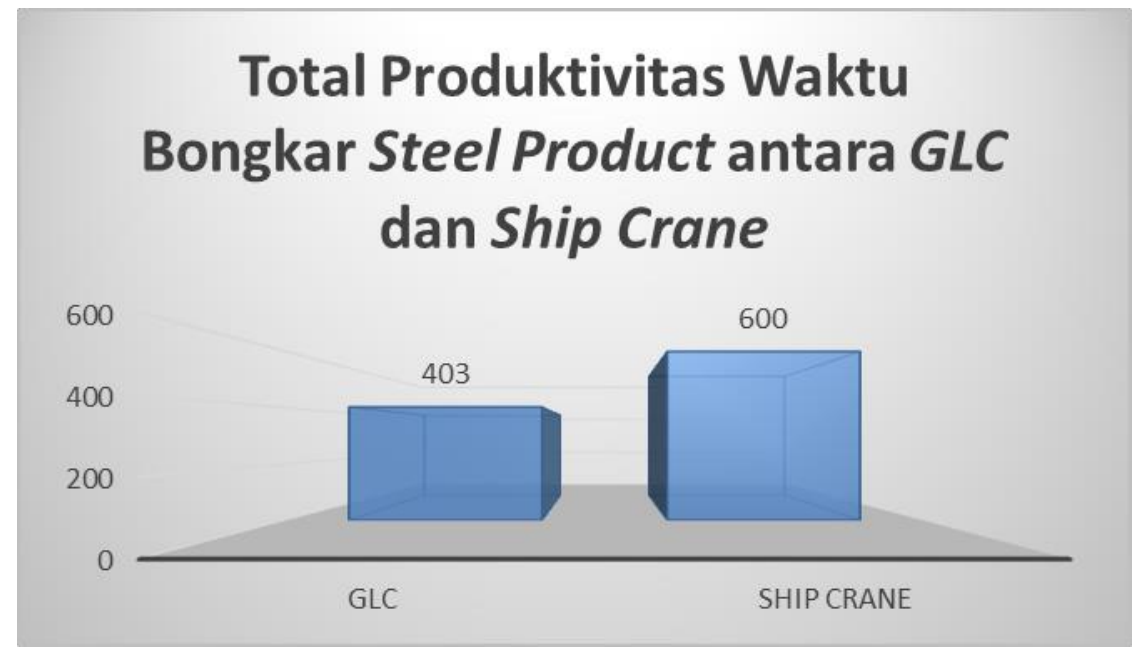

Gambar 3 Hasil Produktivitas Waktu Bongkar Steel Produt Antara GLC dan Ship Crane

Keterangan Gambar :

a. Total keseluruhan waktu lifting Coils 2 ton +8 ton +18 ton +19 ton menggunakan ship crane

283 menit +24 menit +158 menit +15 menit $=480$ menit $($ waktu bersih $)+120$ menit (waktu kotor) : $60=10$ jam

b. Total keseluruhan waktu lifting coils 2 ton +8 ton +18 ton +19 ton menggunakan gantry lifting crane

236 menit +22 menit +105 menit +20 menit $=383$ menit (waktu bersih $)+120$ (waktu kotor) : $60=8$ jam 23 menit

Waktu kotor yang diperlukan untuk bongkar coil terdiri dari:

1. Pada saat menyiapkan alat bongkar sekitar 45 menit 
2. Pegantian sling wire kapasitas $15-30$ ton waktu yang diperlukan 30 menit

3. Lift on/lift off waktu yang di perlukan 30 menit

4. Waktu Persiapan pergantian Shift 15 menit

\section{Simpulan}

Dari berbagai pembahasan dan uraian yang telah dikemukakan diatas, penulis dapat menulis beberapa kesimpulan, antara lain sebagai berikut :

1. Total waktu lifting menggunakan ship crane membutuhkan waktu 10 jam sedangkan menggunakan GLC membutuhkan waktu 8 jam 23 menit lebih efektif. Dari kedua alat tersebut yang lebih produktivitas dalam waktu bongkar steel product yaitu GLC. Sebab alat $G L C$ merupakan alat bongkar yang mempunyai kapasitas daya angkat lifting yg besar.

2. Total lifting menggunakan ship crane lebih banyak yaitu 320 lifting sedangkan GLC lebih sedikit yaitu 169 lifting, semakin sedikit lifting semakin cepat untuk proses bongkar/muat. Jadi dari kedua alat tersebut yang lebih produktivitas dalam lifting yaitu $G L C$. Sebab alat $G L C$ mempunyai daya kapasitas yang sangat besar.

3. Untuk melakukan bongkar steel product harus pre arrival meeting terlebih dahulu sebelum satu hari proses bongkar steel product dilakukan, kemudian sebelum bongkar steel product dilakukan harus mempersiapkan alat-alat bongkar. Setelah kapal sandar lalu kegiatan bongkar dilakukan hingga selesai.

\section{E. Daftar Pustaka}

Andri Kristanto. 2003. Perancangan Sistem Informasi dan Aplikasinya.Penerbit: Gava Media, Jakarta.

Anonim. 1997. Kamus Besar Bahasa Indonesia. Balai Pustaka. Departemen Pendidikan Kebudayaan.

Bowersox, C. 1981. Pengertian Transportasi. New York: Macmillan Publishing Co, Inc.

Departemen Pendidikan Nasional. 2002. Kamus Besar Bahasa Indonesia. Jakarta: Balai Pustaka.

Komaruddin. 2001. Ensiklopedia Manajemen, Edisi ke 5. Jakarta. Bumi Aksara

Nawawi. 1990. Administrasi Personel Untuk Produktivitas Kerja. Jakarta : Haji Masagung.

Republik Indonesia, Undang-Undang No. 17 Tahun 2008 tentang Pelayaran, Lembaran Negara

No. 70 tahun 2008, Tambahan Berita Negara No. 4297.

Sudjatmiko. 1995. Pokok-Pokok Pelayaran Niaga. Bhratara. Jakarta.

Suyono, Capt. R. P. 2005. Shipping Pengangkutan Intermodal Ekspor Impor Melalui Laut. Jakarta: PPM. 
Peraturan Pemerintah Republik Indonesia Nomor 69 Tahun 2001 Tentang Kepelabuhan.

PT. Daisy Mutiara Samudra. 2016. Standar Operasional Prosedur. Jakarta. 